\section{Access to special care dentistry, part 1. Access}

\author{
A. Dougall ${ }^{1}$ and J. Fiske ${ }^{2}$
}

VERIFIABLE CPD PAPER
IN BRIEF

- The majority of people with a mild or moderate disability or medical condition can and should be treated in general dental practice.

- Recent legislation, particularly the Disability Equality Duty, impacts on the responsibility of the dental team to ensure that disabled people are treated equally.

- There are many practical ways of facilitating access for the special care patient.

This first article in the series will define special care dentistry, who requires it and why? It considers recent legislation and its impact on the primary care practitioner, including reasonable adjustments to the way in which dental care is delivered. It offers practical tips to encourage access to the dental practice and transfer to the dental chair and advice on techniques to aid access to the oral cavity for patients with a range of impairments.

\section{INTRODUCTION TO THE SERIES}

The aim of this series is to encourage practitioners to provide access to dental and oral health care for people requiring special care dentistry.

The theme of the articles will be 'Access' in its broadest terms - for

\section{ACCESS TO SPECIAL CARE DENTISTRY}
1. Access
2. Communication
3. Consent
4. Education
5. Safety
6. Special care dentistry services for adolescents and young adults
7. Special care dentistry services for middle-aged people. Part 1
8. Special care dentistry services for middle-aged people. Part 2
9. Special care dentistry services for older people

\footnotetext{
${ }^{1}$ Lecturer and Consultant for Medically Compromised Patients, Division One/Special Care Dentistry, Dublin Dental School and Hospital, Lincoln Place, Dublin 2, Ireland $;{ }^{2 *}$ Chairperson of the Specialist Advisory Group in Special Care Dentistry/Senior Lecturer and Consultant in Special Care Dentistry, Department of Sedation and Special Care Dentistry, King's College London Dental Institute, Floor 26, Guy's Tower, London, SE1 9RT ${ }^{*}$ Correspondence to: Dr Janice Fiske

Email: Janice.Fiske@gstt.nhs.uk
}

example, from access to the NHS to the dental practice; and from how you as a practitioner can access support from specialist services to tips on how to manage individual patients in the surgery setting. The emphasis will be on collaboration between the secondary and primary care services, including the place of 'shared care'. The series is directed at the oral health of adolescents and adults, as children with disability are generally cared for by specialists in paediatric dentistry rather than those in special care dentistry. However, a large proportion of the information and practical tips provided in the series will be transferable between age groups.

The articles are as follows:

1. Access

2. Communication

3. Consent

4. Education

5. Safety

6. Special care dentistry services for adolescents and young adults

7. Special care dentistry services for middle-aged people. Part 1

8. Special care dentistry services for middle-aged people. Part 2

9. Special care dentistry services for older people

The first part of this article will set the background for the series by defining special care dentistry, who requires it and why, who should provide it, and access to National Health Service. The second part looks at patient access and considers the dental practice and surgery, as well as how the dental team gains access to the patient and their mouth.

\section{PART A - SPECIAL CARE DENTISTRY}

\section{What is special care dentistry?}

Special care dentistry (SCD) is described as being concerned with providing and enabling the delivery of oral care for people with an impairment or disability, where this terminology is defined in the broadest of terms as: 'The improvement of oral health of individuals and groups in society who have a physical, sensory, intellectual, mental, medical, emotional or social impairment or disability or, more often, a combination of a number of these factors. ${ }^{1}$ It is defined by a diverse group of people with a range of disabilities and complex additional needs and includes people living at home, in long stay residential care and secure units, as well as people who are homeless. SCD seeks to address the oral health needs of people with a range of primary conditions which may result in their oral health being compromised directly through the condition itself, or indirectly through medication or poor access to care.

This is a very wide definition and in an effort to provide a more objective 
boundary, Faulks and Hennequin ${ }^{2}$ described three groups of people who require SCD:

1. People who experience disability due to impairment of oral function and/or structure and who are limited in their activity and/or participation directly by their oral status

2. People who have a condition that has direct or indirect repercussions on their oral health

3. People who are disabled by their social, environmental or cultural context, which reflects on their oral health.

It is important to remember that not everyone with disability requires SCD, as not all disability limits oral health. Also, those persons able to express need and able to easily access mainstream dental services, despite disability, are not in need of SCD. Whereas, those people unable to express need or unable to access care because of disability (for example, due to reduced communication, fear, inability to co-operate, inappropriate service provision) require SCD. There is also a temporal factor, in that SCD may be required at certain periods or points of an individual's life and not at others. ${ }^{2}$

Faulks and Hennequin suggest that the oral health needs of the three groups could be met through access to affordable, quality dental care and prevention. $^{2}$ Access to appropriate oral care is to a large extent governed by the skills, experience, facilities and/or remuneration available to the dental team. ${ }^{3}$ Whilst acquisition of the first two of these factors sits within the responsibility of the dental team, appropriate remuneration sits firmly within Government responsibility.

The ethos of SCD is a broad-based philosophy of provision of care that takes a holistic view of oral health. ${ }^{1}$ To this end, achievement of the most appropriate preventive and treatment care plan for an individual, tailored to meet their specific needs, is through an integrated care pathway developed through liaison with all those members of that individual's care team, for example dental, medical and social professionals and others. ${ }^{4}$ In

Table 1 Incidence of disability in the UK

\begin{tabular}{l|l}
\hline Type of impairment & Estimated numbers affected \\
\hline Visual impairments & 2 million \\
\hline Hearing impairments & 8.7 million \\
\hline Mobility impairments resulting in wheelchair use & 500,000 \\
\hline Learning difficulties & 1 million \\
\hline Invisible or 'hidden' impairments & 250,000 \\
\hline Arthritis & 8 million \\
\hline Mental health impairments & 1 in 4 of the population
\end{tabular}

accepting this view, there is a recognition that:

- All individuals have a right to equal standards of health and care, including oral health ${ }^{5,6}$

- All individuals have a right to autonomy in relation to decisions made about them ${ }^{5}$

- Good oral health has positive benefits for health, dignity and self-esteem, social integration, and general nutrition, ${ }^{7}$ and

- The impact of poor oral health can be profound.?

\section{The disabled population}

It is estimated that between 8.6 and 10.8 million people in Great Britain have a disability (Table 1$){ }^{8}$ The Disability Partnership describes this as One in four of us, as it is anticipated that the life of one in every four adults in the UK will be effected by disability, either through experiencing a disability or caring for someone close to them who has a disability. ${ }^{9}$

Census data for England and Wales indicates that almost 9.5 million people (18.2\% of the population) self-report a long-term illness, health problem or disability which limits their daily activities or work. ${ }^{4}$ Disability tends to increase with age and multiple disabilities are more likely to occur in old age, with approximately two thirds of all people with a disability being over 65 years of age. Up to 16 years of age, the main causes of disability are genetic and congenital, effecting $4.3 \%$ of the population; from 16 to 49 years the main causes are trauma and neurological conditions, with $9.65 \%$ of the population effected; and in the 50-64 year old population, musculoskeletal, cardiorespiratory and neurological disorders effect $26.65 \%$ of the population.

There is no single register for disability, and a proportion of people with disability have multiple impairments and/or medical conditions and could be on more than one register. For example, people with learning impairments have an increased prevalence of associated disabilities such as physical or sensory impairments, behavioural differences and epilepsy. Furthermore, with ageing, people with learning disabilities also have a higher rate of dementia than the general population.

There is a spectrum of disability, with the majority of people having a minor or moderate disability. For example, many disabled people live at home and are functionally independent, whilst others are dependent on regular support but still live independently or with their families. A relatively small proportion, yet a significant number, of older people live in care homes, accounting for 5\% of all older people. However, the proportion increases with age from $20 \%$ of people aged 85 years and over to $84 \%$ of those aged 95 and over. ${ }^{10}$ These people are amongst those with more complex disability who require specialist skills and management to have their needs met. The Department of Health has recently described people with disability at the highest level of need and dependency as being at the apex of the pyramid spectrum of need. ${ }^{6}$

\section{Oral health needs}

Within the UK, the oral health of adults has improved greatly over the past three decades, with more people retaining 
their teeth into older age and the proportion of denture wearers falling markedly. ${ }^{11}$ This situation presents challenges to the dental profession in providing care for medically compromised, multiply disabled and older people who may require a wide range of interventions in a heavily restored dentition at a time in their lives when they are less able to cope with treatment. ${ }^{12}$

Disabled people want to retain their natural teeth for the same reasons as other people - to look good, retain selfesteem, to be socially acceptable, to be comfortable and to be able to enjoy their food. Whilst it is recognised that they should have equal access to oral healthcare services and equitable oral health outcomes in terms of self-esteem, appearance, social interaction, function and comfort, this is not currently the case. For example, it is well documented that people with learning disability or mental health problems have similar oral diseases but poorer oral health (particularly periodontal health) and health outcomes from care than the general population..$^{5,13,14}$ Additionally, people with learning disabilities living in community settings are less likely to have received dental treatment. ${ }^{15}$ Even when treatment occurs, it is more likely to result in extractions than fillings, crowns and bridges. This is particularly so for people living in residential care, ${ }^{15,16}$ and the situation is similar for people with mental health problems. ${ }^{17}$

\section{Access to NHS dental services}

In recognition of the fact that people requiring SCD generally have needs which are wider than oral health, the British Society for Disability and Oral Health (BSDH) has produced guidelines for oral healthcare and development of integrated oral healthcare pathways to encourage the move towards equitable access, care and outcomes. ${ }^{5,17-22}$

The recent Department of Health document Valuing people's oral health, a good practice guide for improving the oral health of disabled children and adults (2007) recognises the need for the provision of equitable and responsive oral healthcare services for people with disability. ${ }^{6}$ The document is designed to support primary care trusts (PCTs) and their advisers in their needs assessment and commissioning of preventive oral health services rather than considering treatment provision. In his forward to the document, Barry Cockcroft (Chief Dental Officer for England) reminds the reader that the NHS has a responsibility to ensure the equality of provision of care to all groups in society and that, if implemented correctly, the guidance within this document will be of benefit to both PCTs and their dental contractors in improving the oral health of their local disabled residents.

The document recognises that as well as providing responsive oral health services, at the same time "it is important to value and develop competence in provision of oral healthcare to people with disability through research, consistent advice, professional training and provision of specialist care'. ${ }^{6}$ It acknowledges the treatment of preventable dental diseases is costly to the PCTs and specialist services and to patients and their carers. It states that carers may have to take time from work and fund transport to accompany disabled people for treatment, but takes no account of the emotional, psychological, social or financial cost to the disabled person, who may also need to take time from paid employment. However, it provides some prudent key messages including recognition of the need to commission accessible, prevention-focused primary care services, and timely, responsive, needs-led specialist care. ${ }^{6}$

The document states that 'Oral health is everyone's business', by which it means that oral health should be considered in health policy at all levels, with integration of oral health into the mainstream health agenda.

\section{The 2006 NHS dental contract}

A 'new' NHS dental contract was introduced in England in April 2006. ${ }^{23}$ It bestowed the responsibility to commission dental services to meet the needs of the local population on PCTs. They have a duty of care to meet the needs of their local population, including sections of the population with disability, and are likely to identify their priorities in the context of legislation, key national policies, local needs and local service delivery. In deciding how to develop the service, a PCT will probably consider the views of other PCTs, the local oral health advisory group, current service providers such as specialists in SCD, and potential or actual service users. ${ }^{24}$ The recent BSDH publication Commissioning tool for special care dentistry is another useful resource. ${ }^{25}$

To date, the implementation of the 'new' dental contract provides little potential to meet the needs of people with disability. Most PCTs rolled on practice profiles and commissioned those services, or the equivalent, in terms of 'units of dental activity' (UDAs) that were being provided in the test period of the development of the new contract. This remuneration system is based on average time taken to carry out various procedures rather than on the needs of individual patients. It takes no account of the complexity of care, such as the provision of oral care for someone with a learning disability, which may involve dealing with their inability to consent for care; the use of tools such as 'Makaton' and 'Easy Read'; working with advocates; and organising, attending and informing 'best interest meetings'.

UDAs have also been introduced into the contracts of the salaried (formerly known as personal and community) dental services, which have always been a safety net service for people with disability unable to receive care in mainstream general dental services. The new contract has not taken account of the skewed practice profile of complexity of care within salaried dental services and, not surprisingly, there has been anecdotal evidence of the difficulties this has caused in continuing the appropriate provision of care for people with disability.

Additionally the contract provides no possibility for growth of provision for a population that was under-served and/or which is growing, without specific services being commissioned by the local PCT. A particular concern is that, in some areas, because of initial uncertainty of how to approach the issue, rather than rolling on contracts for domiciliary care, none were commissioned thus reducing access to care for vulnerable older people, whom the Department of Health itself describes as 
being at the apex of the pyramid spectrum of need. ${ }^{6}$ Previously, a practitioner could have chosen to expand their NHS service. Now, without additional commissioning of services by the PCT, any further domiciliary care provided by a practitioner is disincentivised as it will be paid in UDAs, with no recognition of the additional time or skills required.

\section{Special care case-mix tool}

The British Dental Association (BDA) has supported the development of a tool, known as the 'case-mix model', which allows objective assessment of the complexity of the provision of care for people with disability through a structured matrix. It allows an evaluation of patient complexity, rather than the complexity of the dentistry being provided, using six independent criteria that, either solely or in combination, indicate a measurable level of patient complexity (Table 2). Each criterion is measured independently on a four point scale (where zero represents an average fit and well individual and $\mathrm{A}, \mathrm{B}$ and $\mathrm{C}$ represent increasing levels of complexity) and covers both actual provision of clinical care and the additional pieces of work needed to facilitate care for many disabled patients.

Currently this is seen as a tool to describe the complexity of the patient. In time, as its robustness improves, its use could be expanded to commissioning and planning of services; benchmarking between services; an individual caseload descriptor; and provision of a measure for appropriate remuneration reflecting levels of case complexity. The case-mix model training pack is available from the BDA website. ${ }^{26}$

\section{Workforce issues}

\section{Current workforce}

Most dentists working in the field of SCD are based in the salaried dental service. ${ }^{27}$ There is a smaller constituent of SCD based in general dental practice (GDP) and teaching hospitals. Whilst general dental practitioners contribute to the overall picture of SCD, only a small number of practitioners currently have a specialist interest in this field. ${ }^{24}$

There is scope for expanding GDP services if the needs and expectations of people with disability and their carers are to be met. For example, an oral health study on the views and experiences of parents of adults with Down Syndrome identified that people want to be treated with the same standards as people without disability, and they desire good access to mainstream dental services with the support of expert or specialist advice, care and facilities as required. ${ }^{28}$ Far from feeling that this was the case, examples of professional diffidence and less than optimal care were cited. ${ }^{28}$ Some concerns have been expressed that mainstreaming people with a disability could result in neglect and that optimal benefits arise from a mix of mainstream services and dedicated services, with access to specialist care when required. ${ }^{29}$

\section{Education and training}

Historically, there has been little, if any, formalised education and training in SCD. This situation is changing. The Teachers' Group for BSDH has developed competencies that should become integral elements of undergraduate training and which will provide all graduates with some experience of SCD. ${ }^{24} 30$

Recent recognition of the specialty of SCD allows the development of a structured workforce to help meet the needs of people with disability. Until the development of the speciality, individuals who have undertaken training in SCD have been responsible for their own training. Its development formalises future training, and the period of mediation will allow recognition of those appropriately experienced as specialists to form the core of the SCD workforce.

\section{The generalist/specialist mix}

The provision of generalist and specialist SCD are areas that PCTs need to pay particular attention to. The majority of people with disability can, and should, be treated by the primary dental care network of general and salaried dental services, with only those people at the complex end of the spectrum of disability requiring specialist care. Those people who are at the severe end of the spectrum of disability, or the apex of the pyramid spectrum of need, should have access to ongoing care from specialists in SCD. Figure 1 sets out how specialists in special care dentistry could integrate to support the primary care dental services (including DwSI), through the provision of training and mentoring programmes in SCD, and oral healthcare for those people with specialist requirements.

\section{The role of Dentists with a Special Interest (DwSI)}

The establishment of DwSI posts has caused some confusion. DwSI is not a career grade post but a PCT-commissioned role. To provide clarity in the field of SCD, BSDH (commissioned by the Department of Health) has developed a competency framework for PCTs on commissioning Dentists with a Special Interest (DwSI) in SCD. This document has achieved Gateway approval and ministerial support. ${ }^{31}$ It outlines the competencies required to become a DwSI as well as the requirements for specialists to mentor and monitor progress.

The work that a DwSI in SCD may be required to undertake will depend upon the needs of the local community and will be specified by the commissioning PCT. The contract for a service provided by a DwSI will specify the core activities being commissioned, the types and number of patients (eg type and/ or severity of disability/complex additional needs) suitable to be referred to the service, together with inclusion and exclusion criteria. There would also be agreed arrangements with the specialist in SCD to support the DwSI and to facilitate the management of complications and complex cases.

\section{The role of the general dental practice team}

It has already been said that the majority of people with a disability have disabilities that are mild or moderate and do not require specialist dental care. Even when specialist care is required, it is often the patient management rather than the dentistry that is complex. The role of the general dental practice team is to provide regular review, routine dental treatment and prevention for the majority of people with mild and moderate disability. It is also to work as part of an integrated care pathway, by recognising 


\begin{tabular}{|c|c|}
\hline Criterion & Type of factor considered \\
\hline 1. Ability to communicate & $\begin{array}{l}\text { Need for interpreter or other means of communication; } \\
\text { degree of learning disability or dementia }\end{array}$ \\
\hline 2. Ability to co-operate & $\begin{array}{l}\text { Additional appointment time or acclimatisation visits required; } \\
\text { need to use sedation or } \mathrm{GA}\end{array}$ \\
\hline 3. Medical status & $\begin{array}{l}\text { Treatment modification required; degree of impact of medical } \\
\text { or psychiatric condition on the provision of care }\end{array}$ \\
\hline 4. Oral risk factors & $\begin{array}{l}\text { Ability to carry out oral hygiene; dietary conditions, eg PEG feeding, } \\
\text { severe xerostomia }\end{array}$ \\
\hline 5. Access to oral care & $\begin{array}{l}\text { Support of carer required to get to the surgery; use of wheelchair } \\
\text { recliner or hoist; need for domiciliary care }\end{array}$ \\
\hline 6. Legal and ethical barriers & $\begin{array}{l}\text { Degree of capacity to consent; need to consult with other professionals } \\
\text { or carers; need to hold best interest meeting or case conference }\end{array}$ \\
\hline
\end{tabular}

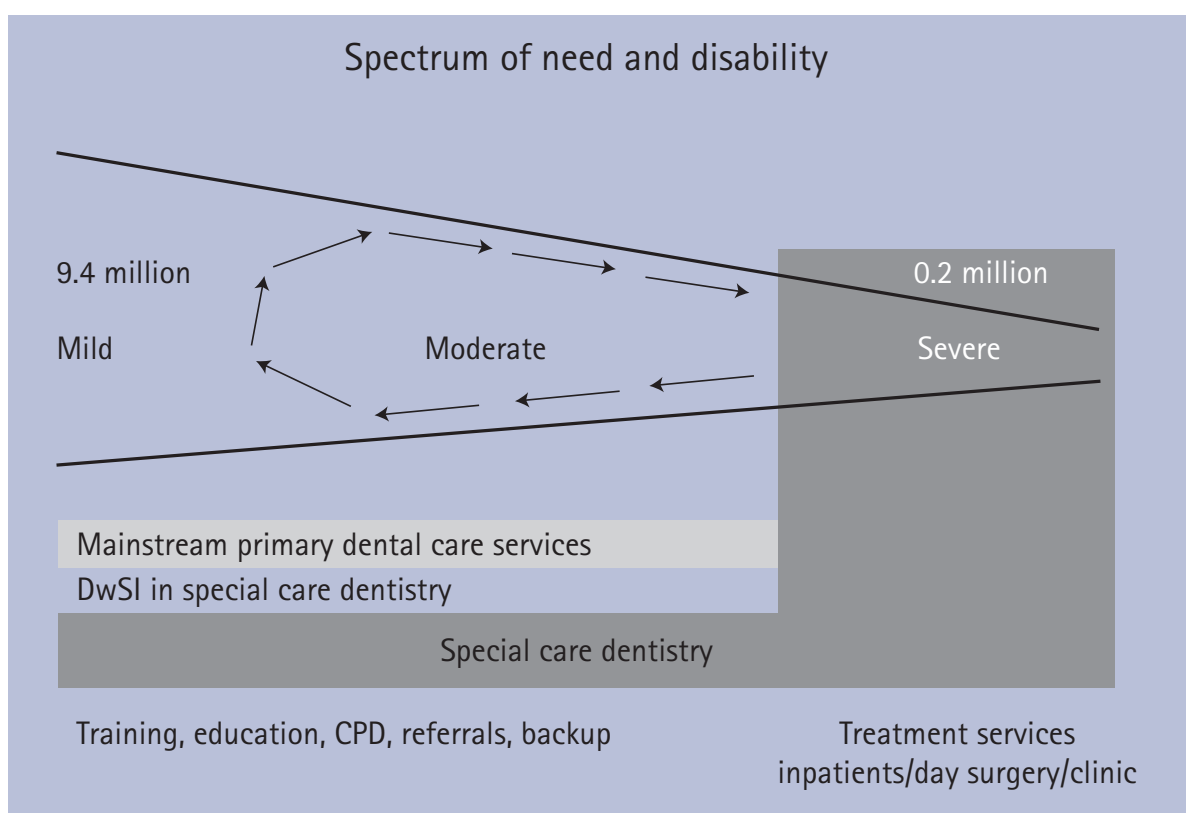

Fig. 1 The integrated role of special care dentists. Source: reference 1. Reproduced with the permission of JACSCD

when additional support or expertise is required and initiating it from the appropriate source. The dentist, dental nurse, hygienist and therapist all have key roles to play. Whilst there is already a SCD qualification for nurses, the one for hygienists/therapists is in development.

Within the SCD workforce, this integrated care pathway provides both timely and appropriate patient care and timely and appropriate support for sectors of the dental profession. It also allows those members of the dental profession who wish to have advice and support in order to develop their skills in caring for people with disability to do so safely under the guidance of more experienced colleagues. In this way, more primary care dentists will feel improved confidence to treat people with disabilities and some may go a step further to develop a specialist practitioner interest.

\section{PART B - PATIENT ACCESS}

\section{Current legislation}

Whilst the impairment will always be important when deciding on clinical treatment, a patient-centred approach is essential to ensure that disabled service users have the same level of access, informed choice and customer service as anyone else. ${ }^{32}$

\section{The Disability Discrimination Act 1995}

In 2002, Edwards and Merry discussed the responsibilities of the dentist in relation to the Disability Discrimination
Act (DDA) 1995 in terms of alterations to buildings and surgeries and changes to service delivery which may be reasonably expected of the general dental practitioner..$^{33-35}$ Their articles gave advice for implementing disability audits and changes during modernisation prior to the introduction of the final part of the DDA 1995 in 2004. ${ }^{36}$ Since then, the final part of this Act has been implemented, such that the current legislation gives disabled people the right to bring a civil claim against a practice that they consider has discriminated against them. Additionally, the Equality and Human Rights Commission (replacing the Disability Rights Commission) opened in October 2007 and can use its new enforcement powers where necessary to guarantee equality to all. Damages that can be awarded by them to a disabled person who has been discriminated against are seemingly limitless. ${ }^{37}$

For the purposes of the Act, a disabled person is described as 'a person who has or has had a physical or mental impairment which has a substantial and long-term adverse effect upon his or her ability to carry out normal day to day duties. ${ }^{36}$ This all-encompassing definition includes people with physical problems including arthritis and back problems. It includes people with a wide range of medical problems such as AIDS, epilepsy, cancer and diabetes, and includes mental health problems such as schizophrenia, stress-related and anxiety disorders, agoraphobia and eating disorders.

The DDA 1995 was introduced in phased stages. In 1996 it became unlawful for service providers, including dentists, to treat disabled people less favourably for a reason related to their disability, for example refusing to allow a person with autism into the waiting room for fear of disturbing other people. By 1999, service providers were required to make reasonable adjustments for disabled people, such as providing extra help or making changes to the way that they provide their service. Examples of good practice included assigning designated wide parking spaces, offering domiciliary visits to people confined to home, producing information leaflets in large type or on audio-tape for people with visual 
impairments, and texting appointments or emailing information to people with a hearing impairment. Finally, in 2004, service providers were required to assess obstacles and make reasonable adjustments to the physical features of their practices to overcome physical barriers. This included, for example, the widening of doorways; installing ramps, stair lifts and/or wheelchair lifts; lowering part of the reception desk for easy access by wheelchair users; clearing corridors and surgeries of obstacles; adding rails to stairs and bathrooms; and improving signage and lighting.

\section{The Disability Equality Duty 2006}

The Disability Equality Duty (DED), part of the Disability Discrimination Act $2005,{ }^{38}$ was introduced in December 2006. It requires that any public body (including service providers) needs to look actively at ways of ensuring that disabled people are treated equally. It necessitates organisations across the public sector (including hospitals, clinics, local and central government, schools and colleges) to tackle disability discrimination in a practical way by introducing policies that actively promote opportunities and so prevent discrimination occurring in the first place. This duty is about inclusiveness. It is about developing and putting into place disability equality plans, embedding equality for disabled people into the culture of public authorities in practical and demonstrable ways through the promotion of equal opportunities and elimination of discrimination, and encouraging positive attitudes towards disabled people. The easiest way to achieve this is to include disability equality into everything (such as practice design, policies, staff training and induction) from the outset, rather than focusing on individualised responses to specific disabled people.

Ensuring better physical access to oral care for disabled patients can be divided into four key areas:

- Access to the building

- Access to the dental surgery

- Access to the dental chair

- Access to the mouth.

\section{Access to the building}

Despite legislation and the clear expectations of the Equality and Human Rights

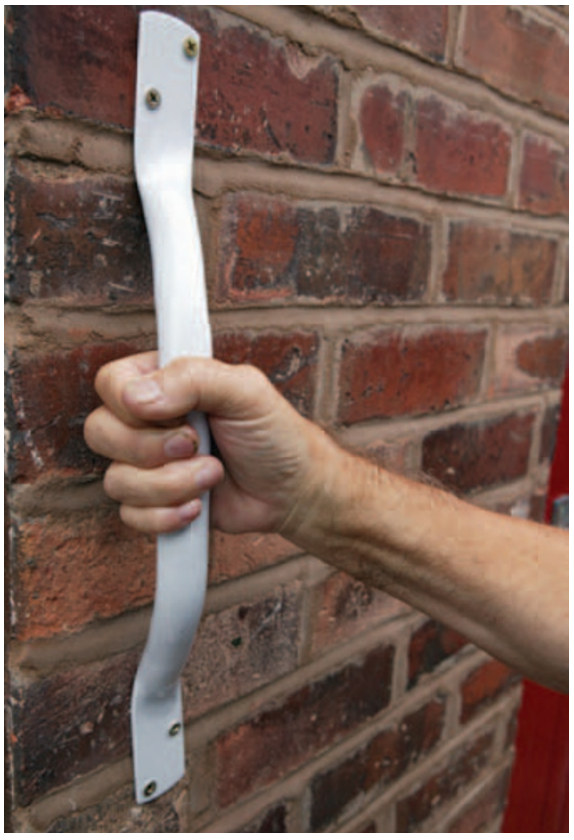

Fig. 2 A simple grab rail can improve access

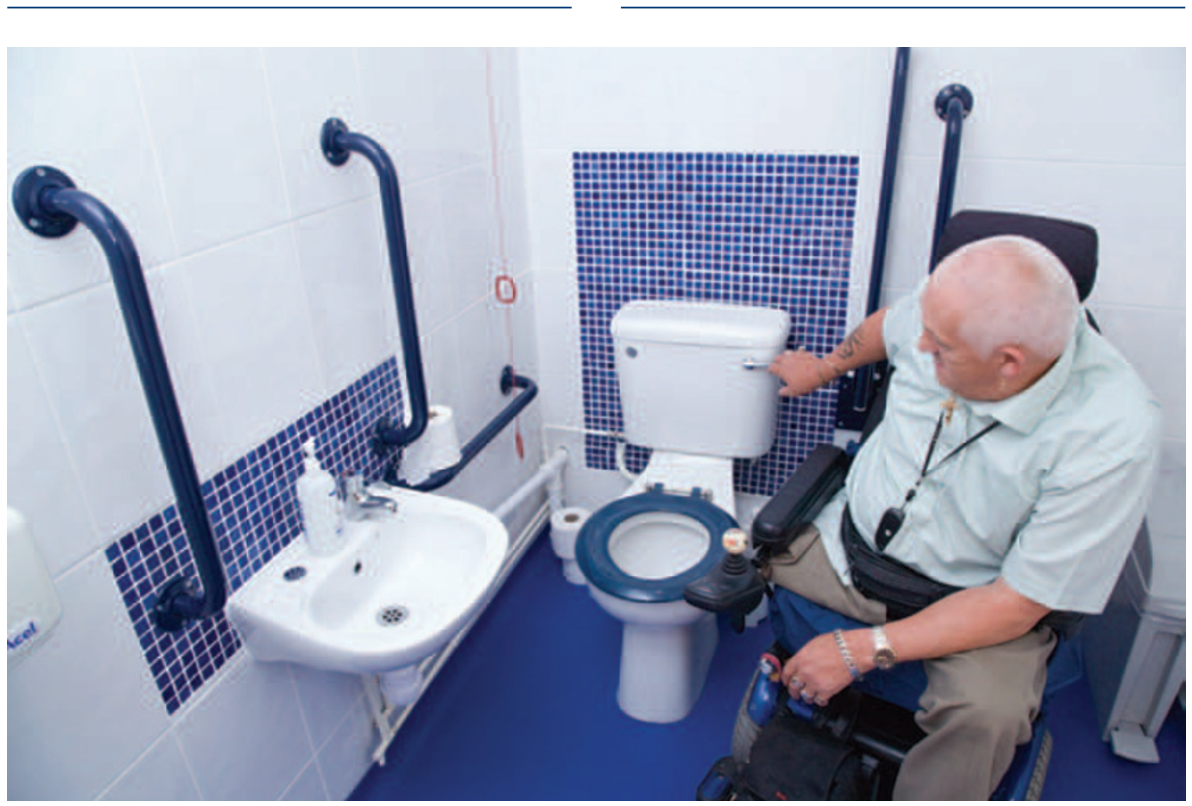

Fig. 4 An accessible toilet

Commission (EHRQ), ${ }^{39}$ physical access to dental surgeries continues to be a barrier to dental patients. ${ }^{40}$ When an individual finds a service difficult to use because of a physical barrier, the EHRQ advises that the law gives the service provider the choice of removing that feature, altering it, finding a way of avoiding it or providing the service in another way. The alternative service must not be unreasonably difficult for the disabled person to use and must not treat them less fairly than someone who can access the building.

Much of the DDA focuses on 'reasonableness'. In many cases simple rails (Fig. 2) and ramps will provide building

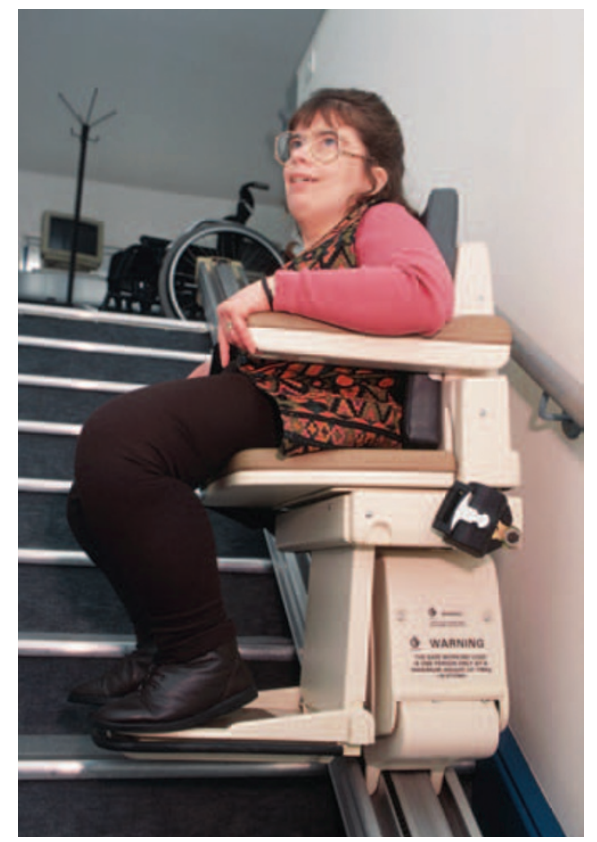

Fig. 3 A stairlift

access for most people with a disability, and major alterations to buildings are only required to provide full access where they are considered reasonable. If a practice is not accessible for a particular person (for example, it is not permissible to make alterations to it because the building is listed), the dentist's duty of care requires them to organise alternative arrangements for treatment which are reasonable and acceptable to the patient.

The impact of the DDA and Building Regulations ${ }^{41}$ governing practice design to ensure access for all can be best seen in new build and modernisation projects. Building regulations are not a panacea 
and it should be noted that the recommended width of a 'part m' standard door is not wide enough to take some of the larger wheelchairs or someone with an assistance dog at their side.

Physical factors are not necessarily the main barrier to accessing a dental practice. Staff attitudes can have the greatest impact. Baird et al. examined the factors influencing the dental attendance of 476 people with multiple sclerosis (MS)..$^{40}$ They found that the majority of their study group were happy with the care they received because the practice staff were understanding of their difficulties. They concluded that both staff attitudes and the way in which services are organised are important to people with disability and can, in part, compensate for physical barriers. The majority of the study participants indicated that they would prefer to stay with their family dentist (or a dentist local to work or home) rather than travel to an accessible practice at a distance. However, as MS symptoms progress, it is likely that the lack of facilities at their local practices and physical barriers to care (which in this study included a lack of suitable parking, accessible toilets and equipment such as hoists or stairlifts (Fig. 3)) will become more of a problem. Few of the study population were aware of the possibility of domiciliary care or specialist care and requested more information on these topics.

\section{Access to the dental surgery}

Several authors have advocated the practice of ongoing and documented disability awareness training for all staff, ${ }^{34,37}$ particularly for reception staff and practice managers who are most often the initial point of contact for new and existing patients, thus acting as the 'gate-keeper' to the practice. The best way of assessing accessibility to the practice is twofold:

1. Ask people with disabilities for their opinions, and

2. Undertake an access audit. ${ }^{37,38}$

Access audits can facilitate the identification of physical barriers to the practice and highlight any hidden barriers which may inadvertently promote discrimination.
Some practitioners have expressed concern that an audit report stating their practice is not fully accessible might make them vulnerable under the terms of the DDA. ${ }^{33}$ In reality, the converse is more likely. If a practitioner can demonstrate they have looked at their practice and made reasonable steps to make it accessible, it puts them in a stronger position to counteract any political litigation. ${ }^{33,37,39}$ If disability discrimination is raised, two initial questions will be asked to establish if there are grounds to proceed. Firstly, 'Could the practice have known about the person's disability?' This takes account of: was the practice informed of the disability; was the disability obvious; or was the practice approached in such a way that it was put on notice of the disability, for example patient contact was made using 'type-talk' or information was requested in an alternative format. Secondly, the question 'Could reasonable adjustments have been made?' will be asked. Only if the answer to both these questions is yes AND reasonable adjustments are not considered to have been made will the discrimination be pursued.

The first step of the access audit process could be to ask patients and staff what barriers they consider disabled patients face when attending the practice. Then, to consider what, if any, measures are already in place and how these might be further improved or developed. Look at potential problem areas such as the approach to the premises (parking, kerbs, ramps, lighting, signage, etc). Examine the entrance including door width, level threshold, door opening, position and design of door handles. Include the reception and waiting room, looking at the height of the reception desk, clear signage, non-slip flooring, communication aids, appropriate seating including chairs with arm rests, and space for wheelchairs. Check there are no obstructions or clutter in the corridors or surgeries. Consider the design and layout of the surgeries to give wheelchair access and manoeuvrability. Check toilet facilities (Fig. 4), including space, transfer bars, raised seat and alarm; and consider means of emergency escape from the premises including signage, visual alarms and accessible exits. Local
Authority disability advisors or one of several commercial companies are able to assist with this.

Simple changes can improve the access to the building with minimal outlay. Having made changes, ensure that they are included in the practice leaflet to raise awareness amongst disabled and able-bodied patients. If domiciliary visits are offered then advertise this, which will also explain to current patients why there may not always be a dentist in attendance at the practice.

\section{Domiciliary care}

If it becomes impossible for current patients to access the surgery after acquiring a disability, for example following stroke, as chronic disease progresses, or as a patient ages, there are several options available by which the dentist can organise alternative delivery of care to ensure the patient is not discriminated against. For example, seeing the patient in a more accessible ground floor surgery in the same practice, or organising care with an alternative practitioner in an accessible practice. ${ }^{33}$ Alternatively, a domiciliary visit could be undertaken to gain insight to the particular problems that face the patient and how these might be overcome. Domiciliary care can also provide the opportunity to liaise with the individual's carer(s), who can offer advice and appropriate information directly. ${ }^{19}$ In some cases it may be appropriate to offer on-going care at home and, in others, to arrange transport to the dental surgery.

Domiciliary equipment required for carrying out assessments or for denture adjustments (such as illuminated dental mirrors and an electric motor) are relatively inexpensive. ${ }^{19}$ Traditionally, domiciliary dental care has been restricted to relatively non-invasive treatments. However, advances in portable equipment now permit more extensive procedures to be carried out away from the dental surgery..$^{19}$ The reader is referred to the BSDH guidelines for the development of standards for domiciliary dental care services for comprehensive information on this topic. ${ }^{19}$

\section{Access to the dental chair}

When considering new equipment purchase or designing a new surgery, it is a 
good idea to assess its suitability for all patients, as encouraged by the DED..$^{38,42}$ It is important to consider whether people with physical disabilities can easily access the preferred dental chair or whether the same model is available with a 'break-leg' facility to ease transfer (Fig. 5). ${ }^{37}$ Aim, if possible, for the surgery to be arranged in such a way that there is room for a wheelchair to be brought alongside the dental chair to aid easier transfer by the patient into the dental chair. This layout also allows for the possibility of treating the patient in their own wheelchair using a variety of headrest attachments. ${ }^{43-45}$ This is never

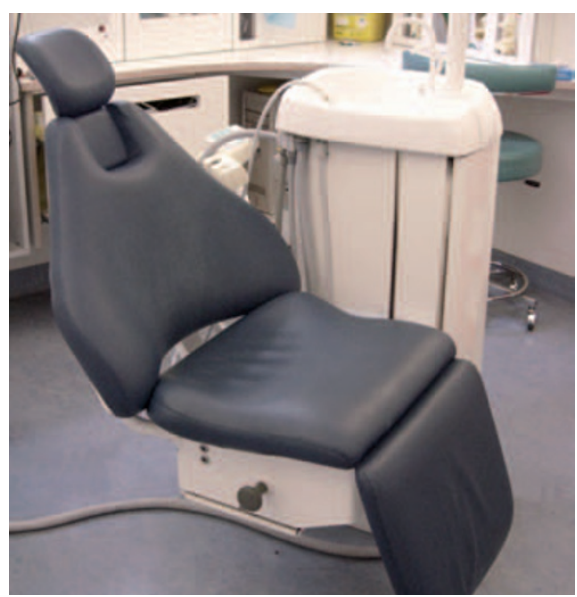

Fig. 5 A break-leg chair allows easy access for people with mobility issues

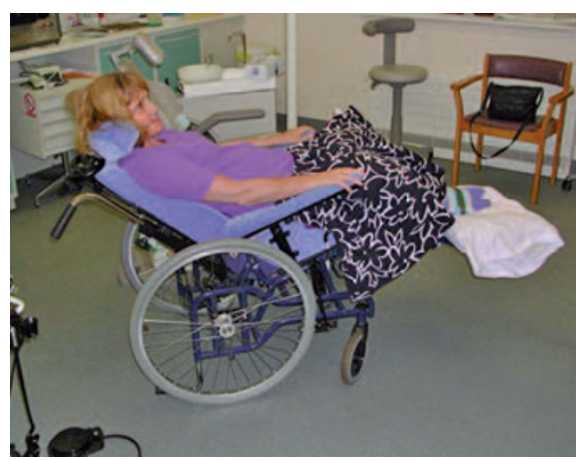

Fig. 6 A reclining wheelchair

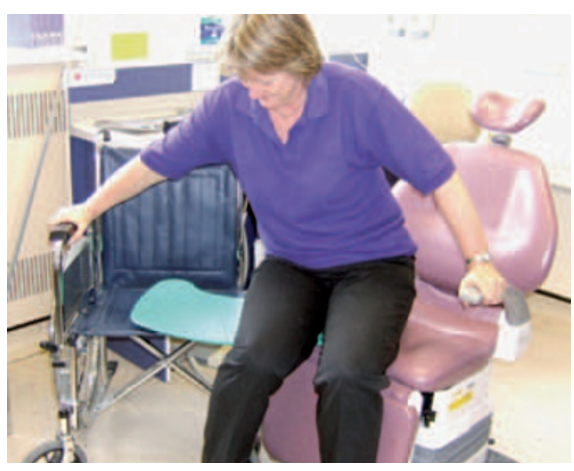

Fig. 7 A banana/transfer board used to 'slide' into the dental chair an ideal option due to the compromised posture of both the operator and patient during treatment, ${ }^{46,47}$ which obviously limits treatment choices and length of appointments. Positioning of both parties may be improved by reclining the back of the patient's own wheelchair, as is possible with many current larger models (Fig. 6). ${ }^{48}$

It is worth remembering that only 5\% of disabled patients who use a wheelchair do so $100 \%$ of the time and most patients with physical disabilities are able to transfer to the dental chair independently. As a general rule it is always prudent to ask the patient how much or little help they require and not to assume that they need help. Furthermore it is important to remember that some people have conditions such as rheumatoid arthritis whereby being touched can be painful, and they may prefer to transfer without help. ${ }^{37}$ When transfer is not straightforward, because the patient cannot stand or weight bear, 'transfer' or 'banana boards' can be used (Fig. 7). This method requires that the dental chair has a breakleg design and is lifted or lowered to the same level as the wheelchair. After the side arm is raised or removed, the smooth curved board (hence the name 'banana board') is placed between the seats to allow the person to slide from the wheelchair to the dental chair or vice versa. Patients can usually transfer themselves or have a carer present who can assist them if required. Many patients who use this method of transfer have their own boards at home which can be brought to appointments. However, it is useful for the practice to have this facility and transfer boards are both cheaply purchased from disability suppliers and easy to store.

A portable turntable can also be a useful device. ${ }^{49}$ It has the advantage of being able to be used with most wheelchair and dental chair designs, and can be used in place of a hoist for some patients (Figs $8 \mathrm{a}$ and b). It is suitable for easy, safe and efficient transfer of patients with paraplegia who have retained good upper body strength and, importantly, is suitable for patients weighing up to $190 \mathrm{~kg}$ (30 stone).

It is not advisable for dental staff to manually transfer or lift patients from their wheelchairs as this can result in damage to the patient (eg dislocation of shoulders) and to the dental staff (eg back injury). A hoist is the best option for safe and efficient transfer of patients unable to do so independently, to the dental chair (Fig. 9). Folding hoists or ceilingmounted models aid storage within the practice and are readily available. Manual handling training of the appropriate level should be locally available within all PCTs. ${ }^{50}$ It should be undertaken and updated regularly, according to local recommendations, by all staff who may need to assist patients with transfers.

Some patients cannot or should not be transferred from their wheelchair for dental treatment and in 2004 a Japanese team developed and evaluated a dental unit suitable for both wheelchairs and general patients. ${ }^{47}$ The base unit offers the option of a dental mounting joint for either a removable dental chair or most commercially manufactured manual wheelchairs. Once attached, either option can be tilted, raised and lowered with no compromise to posture for either the dental nurse or the dentist whilst allowing patients to receive dental treatment in a safe and comfortable position. This design eliminates the risk of accidents during the transfer of patients from wheelchairs to dental units and as the dental unit occupies virtually the same space as a conventional unit, is considered to be readily installable in most dental surgeries. Similar models are now available in the UK and have been installed in a number of primary care units throughout the country. This set up has been well evaluated. Whilst it is compatible with most wheelchairs, it cannot lift sports chairs (because there is no back on them) and, because of the power pack, it cannot accommodate powered chairs. ${ }^{47}$

Recent innovations for patients who should not be moved from their wheelchairs have included fixed and portable wheelchair reclining platforms with integrated head rests (Fig. 10). There are a number of designs now available utilising manual and electronic controls. They eliminate transfer risks to both staff and patients. Not only do they allow patients to remain in their wheelchair throughout the visit, but they are also compatible with all models of wheelchair including 

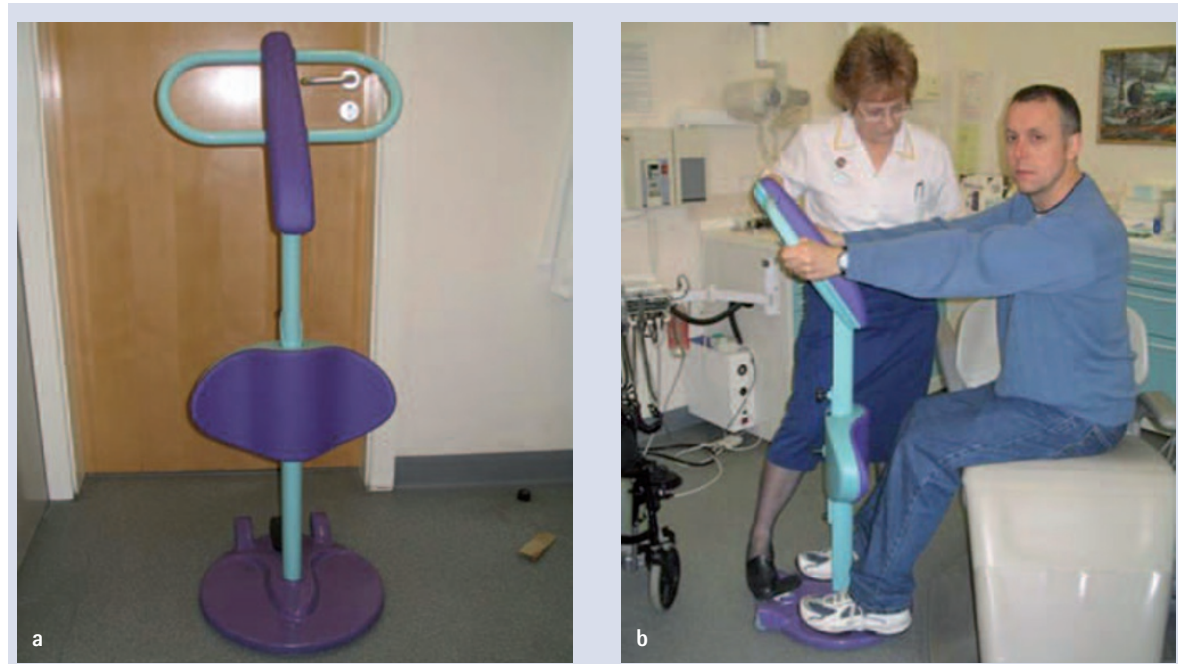

Figs $8 \mathrm{a}$ and $\mathrm{b}$ A portable turntable for transfer of a patient with good upper body strength

large powered models, and can be used for obese patients as their upper weight limit is very generous. They are expensive and are possibly more suited to the specialist practitioner or practices that see a high volume of patients who use wheelchairs.

\section{Access to the mouth}

Access to the mouth can be difficult for a number of reasons. For example, a person with a learning disability or challenging behaviour who does not have the capacity to understand what is required of them in the dental setting and is therefore unable to co-operate. In such an instance, acclimatisation and behavioural techniques can be used to develop rapport and trust and to gain co-operation. Empathy alongside practicality is often the best way to approach the challenge of providing oral care for patients with disability.

In other situations, oral and general muscle control or tone may preclude easy access to the mouth. For those patients who are frail or who have spasticity or hypotonia, cushions can help to create body postures that eliminate the problems that might otherwise interfere with provision of dental treatment. ${ }^{51}$ To achieve the best position in the dental chair, the patient's body should be well supported and joints and muscles should be in the rest position. ${ }^{51}$ Alborg advises that for patients with spasticity, the chin should be as close to the chest as possible and the hips and legs should be flexed and separated to achieve maximal relaxation. However, individuals with a range of impairments might have problems in achieving this posture, especially those patients with rheumatoid arthritis, and some of the neuro-muscular disorders such as multiple sclerosis and cerebral palsy. In these situations she advocates the use of cushions or beanbags to aid in patient positioning and comfort. ${ }^{51}$

The Mun-H-Center in Gothenburg, Sweden, is a National Resource Centre for oro-facial aids and has developed a set of four cushions to provide 'nonsteady anatomical support' in the dental chair (Figs 11a and b). They can be used individually or in combination, depending on the needs of the patient. The crescent shaped cushion is designed to
Fig. 10 A wheelchair recliner by Design Specific

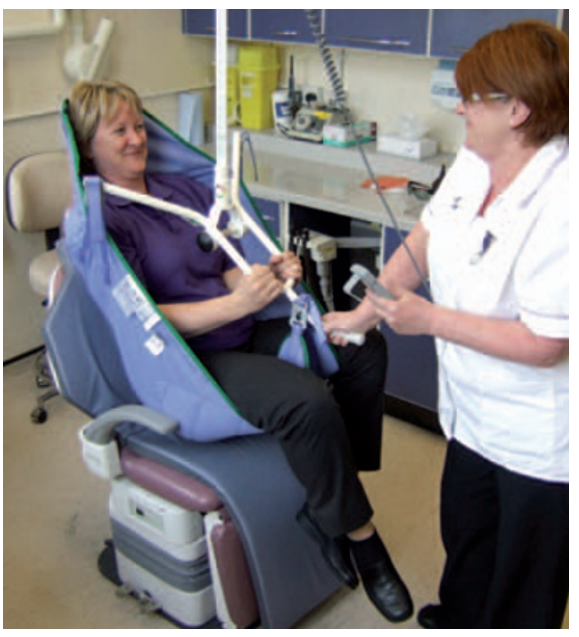

Fig. 9 A patient being transferred from her wheelchair to the dental chair via a ceiling mounted hoist

support the neck. The 'safe-guarder' in the shape of a ring can be placed under the patient's neck and around the shoulders, back and arms. The 'leg relaxer' should be placed under the hollows of the knees and includes a leg-separating portion which can be placed between the knees to prevent the leg extension reflex in patients with spasticity. Finally, the lower leg cushion supports the calves and feet and inhibits any pushing by the feet. The cushions can be fixed together or used independently using Velcro straps. The outer casing is made of cotton, which can be washed at $100^{\circ} \mathrm{F}$, and the body of the cushion can be cleaned with alcohol-based or regular household cleaners or surface disinfectants. ${ }^{51}$

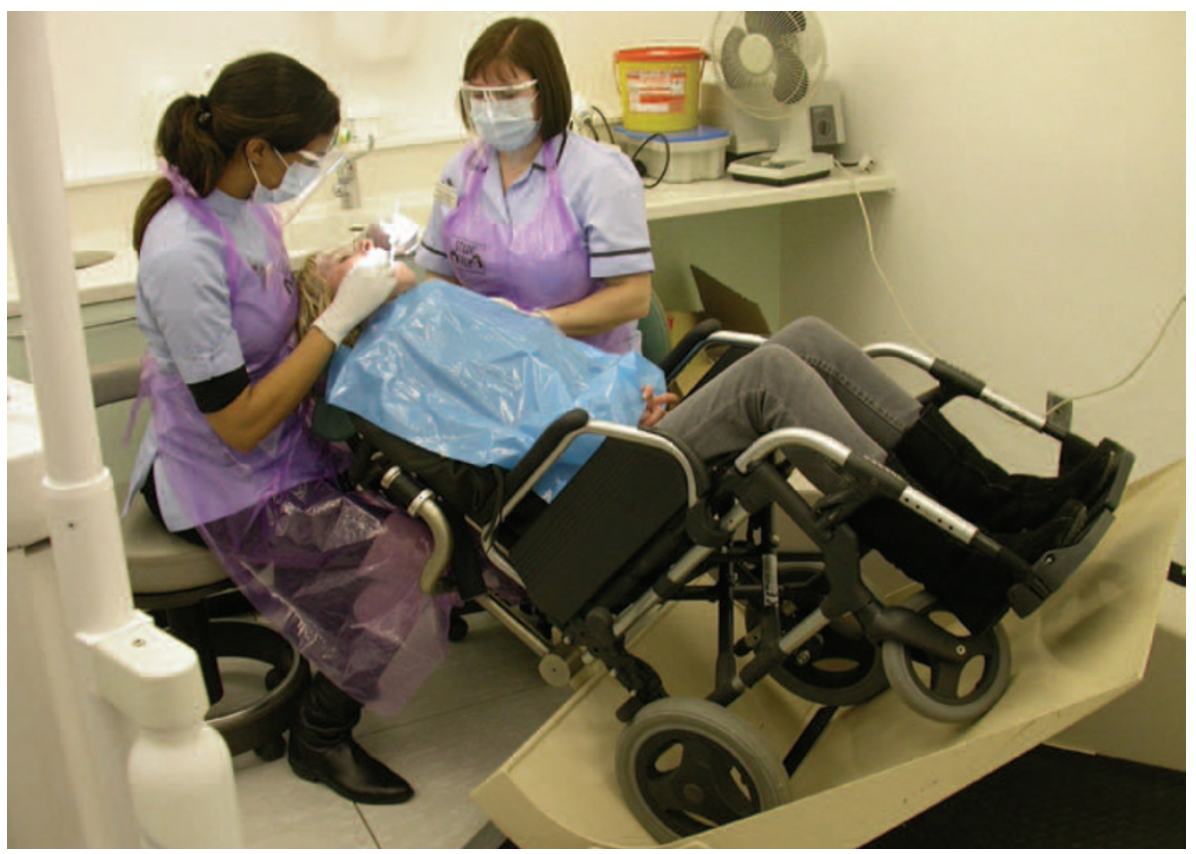


The cushions work on the principle that providing body and neck support to achieve a comfortable and relaxed position (ie slightly flexed rather than hyper-extended) reduces muscle tension in all areas of the body including the oro-facial musculature. As an alternative to custom-made cushions, the use of pillows, horse-shoe shaped travel pillows such as those used for air travel, or pieces of foam have been shown to be effective in supporting the patient in the dental chair. ${ }^{37}$

People with medical conditions, such as chronic obstructive airway disease and congestive cardiac conditions, may need to be treated in the semi-upright position. Care needs to be taken with their positioning. A good gauge of how far they can tolerate being reclined can be made by ascertaining how many cushions the patient uses to sleep at night. The dental chair can then be adjusted to a similar position. ${ }^{45}$

When treating people with a disability such as ataxic cerebral palsy or some intellectual impairments, there may be occasions when consideration has to be given to the risk of the patients inadvertently hurting themselves or the dentist. If the patient has uncontrolled limb movements then safeguards will need to be put in place to prevent them from knocking against equipment or instruments such as handpieces. ${ }^{37}$ Similarly, extra measures should be considered when managing patients who pose a higher risk of inflicting bite wounds on themselves or the operator, for example those patients with exaggerated bite reflexes, uncontrollable muscle spasm (as in cerebral palsy or advanced MS), or challenging behaviour which may be exacerbated by anxiety.

Where there is a risk that the patient may suddenly bite together, this can be mitigated by the use of a bite support or rubber spatula. ${ }^{51}$ The bite support is placed on the finger of the operator or assistant and positioned between the teeth to prevent involuntary clenching of the teeth (Fig. 12). Custom-made options have been successfully used by those operators whose fingers fall between the stock sizes available. ${ }^{52}$ They can be positioned between the maxillary and mandibular molars to check mouth closure.
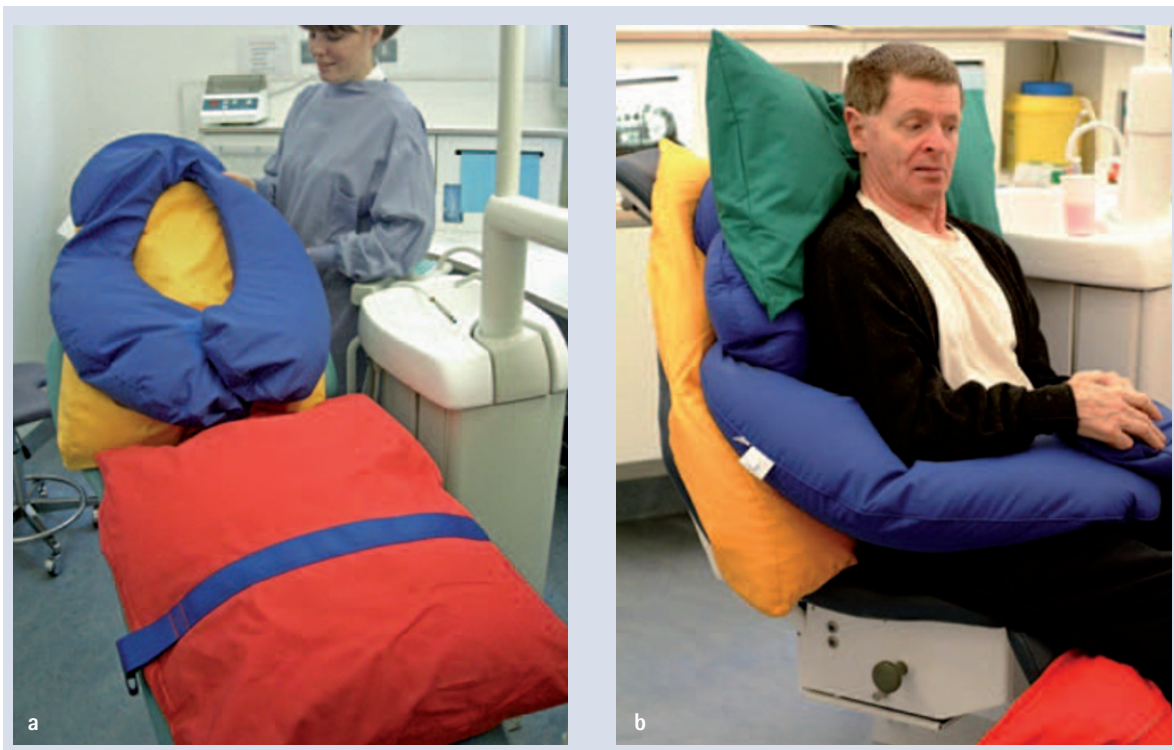

Figs $11 \mathrm{a}$ and $\mathrm{b}$ Support cushions

In addition, unbreakable mirror heads, which can be mounted on traditional mirror handles, have recently become available. Traditional Mckesson props can be used as bite supports for patients who have limited opening or difficulty in maintaining an open position. They serve a dual purpose of preventing biting/clenching and relieving fatigue of the oro-facial musculature. ${ }^{53}$ For patients with high muscle tone and altered motor function, the use of a cheek retractor ${ }^{51}$ of the kind traditionally used for oral photography can assist the patient in keeping their mouth open and their cheeks and lips away from the teeth (Fig. 13). Home practice with the retractor helps to familiarise patients with intellectual disabilities to its use, improving its tolerance in the surgery. The retractor can also be used at home by either the individual or a carer, to assist in access to the teeth during toothbrushing.

Some patients may have either an impaired or an exaggerated gag reflex. People who have an impaired reflex, because of dysphagia or other neurological conditions, may need to be treated in a semi-, or even upright position in order to avoid aspiration of saliva, water spray and other dental debris that could result in aspiration pneumonia. ${ }^{37}$ This can be further avoided by the use of high volume suction and rubber dam. ${ }^{21}$

A pronounced gag reflex can present a barrier to the provision and acceptance of dental care and even simple diagnostic

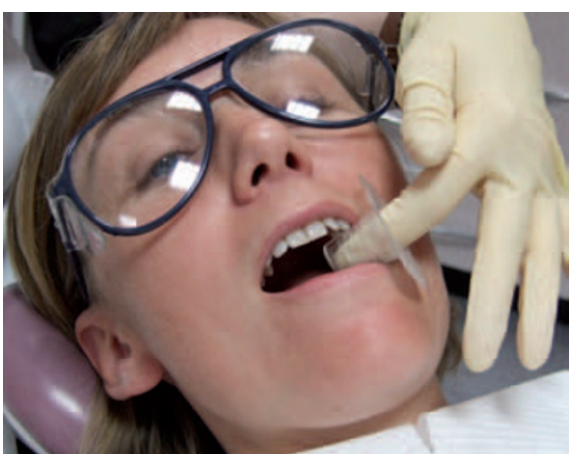

Fig. 12 Bite support used on a gloved finger to help keep the mouth open without effort on the part of the patient

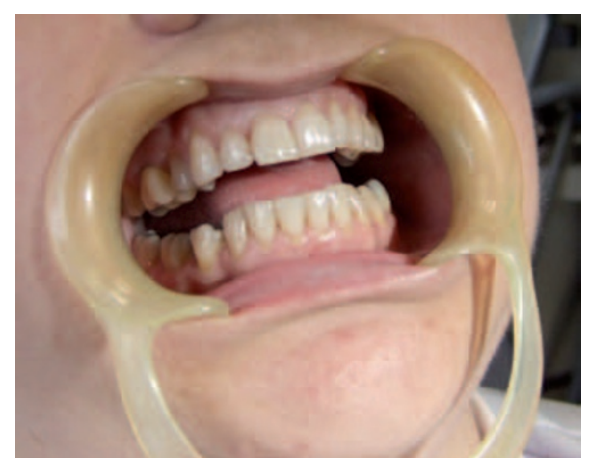

Fig. 13 Using a photographic cheek retractor to hold the soft tissues away from the teeth to improve access

procedures can be compromised. The cause has been described as somatogenic or psychogenic, but is more often a combination of the two, resulting in a conditioned reflex that, at its most severe, can influence the ability to accept oral healthcare to such an extent that treatment planning decisions are severely compromised..$^{5-56}$ In this situation, 
patients need an empathic clinician who takes their problems seriously, and who will be flexible in approach. ${ }^{54}$ Strategies for reducing gagging include relaxation exercises such as deep breathing or selfhypnosis; distraction techniques that use tasks such as raising the legs during a treatment such as impression taking; 55 desensitisation through the use of training plates or tongue exercises; hypnosis; and a wide range of psychological and behavioural therapies. ${ }^{55}$ Conscious sedation techniques using inhalational nitrous oxide and oxygen ${ }^{57}$ or intravenous midazolam ${ }^{58}$ have been shown to work effectively. Morrish has demonstrated suppression and prevention of the gag reflex using a TENS machine during dental procedures ${ }^{59}$ and more recently, both acupuncture ${ }^{60,61}$ and acupressure ${ }^{62}$ have been used effectively to this end. Occasionally, none of these techniques, even in combination, are successful and it is necessary to resort to general anaesthesia (GA) as the only means of guaranteeing control of the exaggerated gag reflex.

Whilst behavioural techniques form the basis for the dental management of disabled patients, in some cases this does not allow the provision of good quality and safe care, particularly for those patients with more profound or complex needs and/or challenging behaviour. In these situations, other adjuncts such as the use of conscious sedation or GA may be required. It has been estimated that $20 \%$ of people with a substantial degree of impairment and who require specialist care, can only be managed successfully with the use of GA. ${ }^{57}$

A recent review of a specialist GA facility concludes that it is both possible and necessary to provide comprehensive oral care for the minority of patients who require this service for dental treatment. ${ }^{63}$ Additionally, the majority of these patients do not require a further course of treatment for some considerable time. ${ }^{63}$ Preventive care is considered a major factor in minimising the need for further treatment under GA. This re-emphasises the requirement for an appropriate approach to shared care through a well developed network of SCD within the primary and secondary care sectors that allows patients to move seamlessly between services and to be seen by the right person, in the right place, at the right time.

The illustrative material used in Figures 2, 3 and 4 is credited to www.johnbirdsall.co.uk.

1. Joint Advisory Committee for Special Care Dentistry. A case for need: proposal for a speciality in special care dentistry. BSDH, 2003. http:// www.bsdh.org.uk/misc/ACase4Need.pdf

2. Faulks D, Hennequin M. Defining the population requiring special care dentistry using the international classification of functioning, disability and health - a personal view. J Disabil Oral Health 2006; 3: 143-152

3. Fiske J, McGeoch R J, Savidge G, Smith M. The treatment needs of adults with inherited bleeding disorders. J Disabil Oral Health 2002; 3: 59-61.

4. Fiske J. The relationship between specialist and general dental practice. CPD Dent 2007; 6: 42-48.

5. British Society for Disability and Oral Health and The Royal College of Surgeons of England. Clinical guidelines and integrated care pathways for the oral health care of people with learning disabilities. London: BSDH, 2000. http://www.bsdh.org. uk/guidelines/Dianatru.pdf

6. Department of Health. Valuing people's oral health. A good practice guide for improving the oral health of disabled children and adults. London: Department of Health, 2007.

7. Locker D. Does dental care improve the oral health of older adults? Community Dent Health 2001; 18: 7-15.

8. Fiske J, Dickinson C, Boyle C, Rafique S, Boyle M. Understanding special care dentistry. In Special care dentistry. pp 1-8. London: Quintessence Publishing, 2007.

9. The Disability Partnership. One in four of us - the experience of disability. Yatton: Triangle, 2004.

10. Fiske J, Frenkel H, Griffiths J, Jones V. Guidelines for the development of local standards of oral health care for people with dementia. Gerodontology 2006; 23 (Suppl 1): 5-32.

11. Kelly $M$, Steele J, Nuttall $N$ et al. The adult dental health survey. Oral health in the UK, 1998. London: The Stationery Office, 2000.

12. National Working Group for Older People. Meeting the challenges of oral health for older people: a strategic review. Gerodontology 2005; 22 (Suppl 2): 3-48.

13. British Dental Association. Oral healthcare for older people: 2020 vision. London: British Dental Association, 2003.

14. Machuca G, Nieves E, Sanchez A F, Machuca C, Bullon P. Descriptive study factors modifying the periodontal status of a population of people with a learning disability in Spain. J Disabil Oral Health 2007: 8: 73-80.

15. Tiller S, Wilson K J, Gallagher J E. Oral health status and dental service use of adults with learning disabilities living in residential institutions and in the community. Community Dent Health 2001; 18: 167-171.

16. Lawton L. Providing dental care for special patients - tips for the general dentists. J Am Dent Assoc 2002; 133: 1666-1679.

17. British Society for Disability and Oral Health. Oral health care for people with mental health problems: guidelines and recommendations. BSDH, 2000. http://www.bsdh.org.uk/guidelines/mental.pdf

18. British Society for Disability and Oral Health. Guidelines for oral health care for long-stay patients and residents. BSDH, 2000. http://www. bsdh.org.uk/guidelines/longstay.pdf

19. British Society for Disability and Oral Health. The development of standards for domiciliary dental care services: guidelines and recommendations. BSDH, 2000. http://www.bsdh.org.uk/guidelines/ domicil.pdf

20. British Society for Disability and Oral Health. Guidelines for oral health care for people with a physical disability. BSDH, 2000. http://www.bsdh. org.uk/guidelines/physical.pdf
21. British Society for Disability and Oral Health. Guidelines for the development of local standards of oral health care for dependent, dysphagic, critically and terminally ill patients. BSDH, 2000. http://www.bsdh.org.uk/guidelines/depend.pdf

22. Clinical Effectiveness Committee, Faculty of Dental Surgery of the Royal College of Surgeons of England. Multi-disciplinary guidelines for the oral management of patients following oncology treatment. BSDH, 2000. http://www.bsdh.org. uk/guidelines/oncolradio.pdf

23. Department of Health. NHS primary dental care services: implementation of local commissioning. London: Department of Health, 2005. Gateway ref. 5641 .

24. Gallagher J E, Fiske J. Special care dentistry - a professional challenge. Br Dent J 2007: 202: 619-629.

25. British Society for Disability and Oral Health. Com missioning tool for special care dentistry. BSDH, 2006. http://www.bsdh.org.uk/misc/Commissioning_Tool_for_Special_Care_Dentistry_FINAL_ MARCH_2007.pdf

26. British Dental Association. Case-mix model training pack. London: BDA, 2007.

27. Hunter M L, Hunter B, Thompson S A, MacLaughlin W S. Special care dentistry: attitudes of specialists in restorative dentistry practising in the United Kingdom towards the creation of a new specialty. J Disabil Oral Health 2004; 6: 19-24.

28. Kaye P L, Fiske J, Bower E J, Newton J T, Fenlon M. Views and experiences of parents and siblings of adults with Down Syndrome regarding oral healthcare: a qualitative and quantitative study. Br Dent J 2005: 198: 571-578.

29. Pratelli P, Gelbier S. Perceived availability and use of dental services by adults with a learning disability living in private households within Lambeth, Southwark and Lewisham. Kings's College, London: Department of Oral Health Services Research and Dental Public Health, 2000 (unpublished).

30. British Society for Disability and Oral Health. Developing an undergraduate curriculum in special care dentistry. BSDH, 2004. http://www.bsdh.org. uk/misc/Teaching doc 06july04.pdf

31. Jenner A. Oral presentation at the spring scientific conference of the British Society for the Study of Community Dentistry, Cambridge 2006.

32. Goss N. Greater expectation - meeting the needs of the disabled service user. Oral presentation at BDA Conference and Exhibition, Birmingham 2006.

33. Edwards D, Merry A, Pealing R. Disability part 3: improving access to dental practices in Merseyside. Br Dent J 2002; 193: 317-319.

34. Edwards D, Merry A, Pealing R. Disability part 2: access to dental services for disabled people. A questionnaire survey of dental practices in Merseyside. Br Dent J 2002; 193: 253-255.

35. Edwards D, Merry A, Pealing R. Disability part 1: the disability discrimination act (1995) - implications for dentists. Br Dent J 2002; 193: 199-201.

36. Disability Discrimination Act 1995, Chapter 50. Office of Public Sector Information. www.opsi.gov. uk/ACTS/acts1995/Ukpga_19950050_en_1.htm

37. Fiske J, Dickinson $C$, Boyle $\bar{C}$, Rafique $\bar{S}$, Boyle $M$. Managing the health of patients with physical disabilities. In Special care dentistry. pp 9-26. London: Quintessence Publishing, 2007.

38. Disability Rights Commission. Doing the duty - an overview of the Disability Equality Duty for the public sector. London: Equality and Human Rights Commission, 2006. http://www.dotheduty. org/files/Doing_The_Duty.pdf

39. The Equality and Human Rights Commission website. http://www.equalityhumanrights.com/ en/Pages/default.aspx (accessed 14 May 2008).

40. Baird W, McGrother C, Abrams K, Dugmore C, Jackson $\mathrm{R}$. Factors that influence the dental attendance pattern and maintenance of oral health for people with multiple sclerosis. Br Dent J 2007; 202: E4.

41. The Building Regulations 2000. Approved document M. Access to and use of buildings. London: Office of the Deputy Prime Minister, 2004. http:// www.planningportal.gov.uk/england/professionals/en/4000000000988.htm

42. Disability Discrimination Act 2005, Chapter 13. 
Office of Public Sector Information. http://www. opsi.gov.uk/ACTS/acts2005/ukpga_20050013_en_1

43. McGhay R M. A simple headrest for patients confined to a wheelchair. J Prosthet Dent 1980; 44: 347-349.

44. McGowan R. Headrest for patients in wheelchairs. Br Dent J 1974; 136: 203-204.

45. Wilkins E M. Patients with special needs. In Clinical practice of the dental hygienist. 9th ed. Section 7. Philadelphia: Lippincott, Williams \& Wilkins, 2004.

46. Sasaki K, Watanabe M, Tamazawa Y. A special clinic for the elderly at a centre of dental clinics. Gerodontology 1997; 11: 281-282.

47. Tamazawa $Y$ Watanabe $M$, Kikuchi $M$ et al. A new dental unit for both patients in wheelchairs and general patients. Gerodontology 2004; 21: 53-59.

48. Walton $\mathrm{G}$. Wheelchair for single transfer of disabled patients. J Disabil Oral Health 2000; 1: 31.

49. Watt-Smith P, Walton G. A case study on the use of turntable transfer. J Disabil Oral Health 2007; 8: $132-134$

50. The Manual Handling Operations Regulations 1992. London: The Stationery Office, 1992. www.
opsi.gov.uk/SI/si1992/Uksi_19922793_en_1.htm

51. Ahlborg B. Practical prevention. In Nunn J (ed) Disability and oral care. Chapter 2. London: FDI World Dental Press, 2001.

52. Geary J L, Kinirons M J. Stock fit as an alternative to custom finger guard mouth props for examination and treatment of patients with special needs. J Disabil Oral Health 2005; 6: 93-97.

53. Harrell S. Managing slightly uncooperative pediatric patients. J Am Dent Assoc 2003; 134: 1613-1614.

54. Fiske J, Dickinson C, Boyle C, Rafique S, Boyle M. Managing pronounced gag reflexes. In Special care dentistry. pp 115-130. London: Quintessence Publishing, 2007.

55. Dickinson C, Fiske J. A review of gagging problems in dentistry: 2. Clinical assessment and management. SADJ 2006; 61: 258-262.

56. Dickinson C, Fiske J. A review of gagging problems in dentistry: aetiology and classification. SADJ 2006; 61: 208-210.

57. Fiske J, Dickinson C, Boyle C, Rafique S, Boyle M. Sedation and general anaesthesia in special care dentistry. In Special care dentistry. pp 139-146. London: Quintessence Publishing, 2007.

58. Tohuku J. Management of exaggerated gag reflex using intravenous sedation in prosthodontic treatment. J Exp Med 2007; 212: 373-378.

59. Morrish R J. Suppression and prevention of the gag reflex with a TENS device during dental procedures. Gen Dent 1997; 45: 498-501.

60. Fiske J, Dickinson C. The role of acupuncture in controlling the gagging reflex using a review of ten cases. Br Dent J 2001; 190: 611-613.

61. Rosted P, Bundgaard M, Fiske J, Pedersen A. The use of acupuncture in controlling the gag reflex in patients requiring an upper alginate impression: an audit. Br Dent J 2006; 201: 721-725.

62. Rosted P, Andersen C. Use of stimulation techniques in pain treatment. Ugeskr Laeger [English Abstract Review] 2006; 168: 1982-1986.

63. Graham F, Kinirons M J, Holland T. An analysis of the pattern of treatment provided for patients with disabilities requiring treatment under general anaesthesia. J Disabil Oral Health 2007; 8: 9-12. 